\title{
Stroop interference effects in partially colored Stroop words
}

\author{
SHAI DANZIGER \\ Ben Gurion University of the Negev, Beer-Sheva, Israel \\ ANGELES F. ESTÉVEZ \\ University of Almería, Almería, Spain \\ and \\ PALOMA MARÍ-BEFFA \\ University of Wales, Bangor, Wales
}

\begin{abstract}
In the Stroop task, word reading is thought to be automatic since it runs without intentional monitoring and is difficult to avoid. This view has recently been challenged by observations that Stroop interference is reduced when only part of the Stroop word is colored. In this study we asked whether the extent of Stroop interference varies with the position of the colored letter(s). We observed that Stroop interference was smallest when the first letter(s) were colored and largest when either the last letter(s) or whole word were colored. On these findings we suggest that colored and noncolored parts of partially colored words are processed separately and differently, and that selection of the color dimension for explicit report entails inhibition of the to-be-ignored colored letters.
\end{abstract}

Through extensive practice, humans can become proficient readers. In fact, they become such skilled readers that they find it difficult to overcome semantic processing of single words where there is a clear incentive to do so. Such is the case in the Stroop task (Stroop, 1935; for a review see MacLeod, 1991), where observers indicate the color in which visually presented letter strings are displayed. For example, observers usually take longer to report an ink color when it is incongruent with a color indicated by a word (e.g., the word green written in red ink) than when the two are congruent (e.g., the word red in red ink) or when a neutral stimulus is used (e.g., the letter string XXXX written in red ink). The Stroop effect is thought to reflect automatic reading because word recognition in the Stroop task runs without intentional monitoring (Bibi, Tzelgov, \& Henik, 2000).

The degree to which word reading in the Stroop task is automatic has been the subject of several studies. Kahneman and Henik (1981; see also Kahneman \& Chajczyk, 1983), for example, asked whether Stroop interference is attenuated when fewer attentional resources are available to process the written word. If so, then on the view that automatic processes do not require attention, word reading in the Stroop task could not be considered strongly automatic. In this study, observers named the ink color of a color printed word that appeared simultaneously with a

Correspondence should be addressed to S. Danziger, School of Management, Ben Gurion University of the Negev, P. O. Box 653, Beer Sheva, 84105, Israel (e-mail: shaidanz@bgumail.bgu.ac.il). word printed in black. There were two critical conditions. In one condition, the color printed word was a color name (blue) and the word printed in black was a noncolor word (most). In the other condition, the color printed word was a noncolor word (most) and the word printed in black was a color name (blue). Kahneman and Henik found large effects of the direction of attention on the extent of Stroop interference. Although Stroop effects were large when the color word was printed in color, they were absent when the noncolor word was printed in color. On these findings it was concluded that word reading in the Stroop task depends on the allocation of spatial attention and therefore cannot be considered strongly automatic.

Recently Besner and colleagues (Besner \& Stolz, 1999a, 1999b; Besner, Stolz, \& Boutilier, 1997) have also challenged the idea that word reading in the Stroop task is strongly automatic. In a series of experiments, Besner et al. demonstrated that when only a single letter of a Stroop word is colored, Stroop interference is reduced and in some circumstances even eliminated. On this finding they also concluded that word reading in the Stroop task is not strongly automatic. In a subsequent study, we asked whether the elimination of the Stroop effect in the single letter colored Stroop task is sufficient evidence for concluding that word reading and semantic processing do not occur (MaríBeffa, Estévez, \& Danziger, 2000). Combining Besner et al.'s (1997) manipulation with a negative priming procedure, we found intact negative priming from a singleletter color prime word in the absence of a Stroop effect (for a replication of negative priming in the single letter colored Stroop task, see Besner, 2001). This result indi- 
cates that the prime word was processed for meaning in the interval between the appearance of the prime and selection of the probe response.

In this study the effects of single-letter coloring on word reading in the Stroop task were explored further. Specifically, we asked whether the extent of Stroop interference changes as a function of the position of the colored letter. Several potential outcomes were envisioned. The first was that Stroop interference would not change as a function of the position of the colored letter. Depending on the size of Stroop interference, such a finding would indicate that coloring a single letter either partially or totally blocks word reading processes in a nonspatially sensitive manner. A second possible outcome, which was consistent with the idea that word reading processes are engaged in the single letter colored Stroop task, was that Stroop interference would change as a function of colored letter position. One scenario that could yield such a result would be that single-letter coloring led to separate and different processing for the colored and noncolored letter strings. On the view that phonemes from the beginning of a letter string more strongly activate the nonlexical route to word reading than phonemes from the end of the word (Coltheart \& Rastle, 1994; Coltheart, Woollams, Kinoshita, $\&$ Perry, 1999), one possible outcome is more Stroop interference when the first letter is colored and attention is directed to the beginning of the word than when it is directed to the end of the word. Alternatively, Stroop interference may be larger when the last letter of a word is colored, because in this case the intact letter segment from the beginning of the word (for example, blu in the word blue) is longer than when the first letter is colored ( $b$ in the word blue).

Several observations indicate that position effects are likely in the single letter colored version of the Stroop task. First, Singer, Lappin, and Moore (1975) found that naming latencies for word lists were longer when the items were color names incongruent with their ink color, and with their middle or final letters deleted or altered (e.g., orxxge, or, and oranxx), than when the items were color names incongruent with their ink color and with their initial or middle letters deleted or altered (e.g., xxange, an, and ge). More recently, Coltheart et al. (1999) observed faster color naming when the first phoneme was shared between a nonsemantically related word and a color word and the ink color was the same as that indicated by the first phoneme (e.g., ram and hip instead of red colored in red), than when the last phoneme was shared (e.g., bed instead of red colored in red). Finally, in a naming task, Bibi et al. (2000) reported that Stroop effects were smallest when the first letter of a color word was replaced, resulting in a noncolor word (e.g., bed instead of red), and largest when the last letter was replaced (e.g., greed instead of green). Coltheart and colleagues (1999) interpreted this pattern of interference effects as evidence for a grapheme-to-phoneme correspondence route to reading and implemented them in their dual-route cascade model. If in the single letter colored Stroop task word reading processes via the nonlexical route are activated, and the letter position to which attention is directed is not important, then we may expect more Stroop interference in the end letter colored condition because here the initial letter segment would be longer than in the beginning letter colored condition.

\section{EXPERIMENT 1}

\section{Method}

Participants. A total of 22 observers from the University of Almería participated for partial fulfillment of a course requirement. All of the participants were right handed, reported normal or correctedto-normal visual acuity, and were not aware of the experiment's purpose.

Stimuli and Materials. The word stimuli consisted of the four Spanish color words rojo, azul, verde, and blanco (red, blue, green, and white). Letter strings consisting of Xs that matched the length of the color words were used as neutrals (e.g., XXXX for rojo and $a z u l$ ). The letter strings and words were colored in red (ASCII Code 4), blue (ASCII Code 9), green (ASCII Code 2), and white (ASCII Code 15) and appeared on a black background. In the whole word colored condition, every letter appeared in the same color. In the single letter colored condition, one letter was colored and the remaining letters appeared in gray (ASCII Code 8). The stimuli always appeared in a color different from that indicated by the meaning of the word or by the length of the string of Xs (e.g., the string XXXX would never be written in those colors containing four letters in Spanish). Thus, the word stimuli were always incongruent. During the experiment each ink color appeared an equal number of times. At a viewing distance of $60 \mathrm{~cm}$, each character was $0.48^{\circ}$ of visual angle high and $0.38^{\circ}$ of visual angle wide. The average length of the strings was $2.86^{\circ}$ of visual angle, varying from $2.29^{\circ}$ to $3.81^{\circ}$.

Stimuli appeared centered at fixation on a color monitor controlled by a Pentium-compatible PC with a VGA card. Stimulus presentation and response acquisition were computer controlled.

Design and Procedure. Each trial began with the appearance of a fixation cross, which after $350 \mathrm{msec}$ was replaced by a letter string in the same location. Participants were instructed to report the color of each letter string as quickly and as accurately as possible while ignoring the letter string. Following each response, a 150-msec interval was included to provide auditory feedback for errors. Participants responded to the four target colors by pressing one of four keys on the keyboard $(>,<, \mathrm{X}$, and $\mathrm{Z}$ ) with the corresponding index and middle finger of each hand. The pairings of color and response key were counterbalanced across participants.

Each participant performed two blocks of 192 test trials in a different random order. In each block there were 96 trials in which only one letter was colored and 96 trials in which all the letters were colored. Of the 96 trials in which all letters were colored, 48 were word trials and 48 were Xs trials. The comparison of these conditions yielded the standard whole word Stroop effect. Of the 96 singleletter colored trials, the colored letter occupied the first position of the letter string on 12 of the word trials and 12 of the Xs trials (begin condition), any of the intermediate positions on 24 of the word trials and 24 of the Xs trials (middle condition), and the last position on 12 of the word trials and 12 of the Xs trials (end condition). Although our predictions were concerned with the beginning and end letters colored conditions, the middle position colored condition was included to avoid polarization of the color search to the extreme positions.

Thirty-two practice trials that mirrored the composition of the test trials preceded the test trials. Instructions that emphasized response speed and accuracy preceded each block of trials.

\section{Results}

The reaction time (RT) analysis included only correct response trials. Trials with RTs shorter than $100 \mathrm{msec}$ or 
Table 1

Response Data for Experiments 1, 2, and 3

\begin{tabular}{|c|c|c|c|c|c|c|c|c|c|c|c|}
\hline \multirow[b]{3}{*}{ Variable } & \multicolumn{3}{|c|}{ Experiment 1} & \multicolumn{3}{|c|}{ Experiment 2} & \multicolumn{5}{|c|}{ Experiment 3} \\
\hline & \multicolumn{2}{|c|}{ RT } & \multirow{2}{*}{$\begin{array}{l}\text { Stroop Effect } \\
\text { (Word-XXX) }\end{array}$} & \multicolumn{2}{|c|}{ RT } & \multirow{2}{*}{$\begin{array}{l}\text { Stroop Effect } \\
\text { (Word-XXX) }\end{array}$} & \multicolumn{3}{|c|}{$\begin{array}{r}\mathrm{RT} \\
\end{array}$} & \multirow{2}{*}{$\begin{array}{l}\text { Stroop Effect } \\
\text { (Word-Body) }\end{array}$} & \multirow{2}{*}{$\begin{array}{l}\text { Stroop Effect } \\
\text { (Word-XXX) }\end{array}$} \\
\hline & Word & $\mathrm{XXX}$ & & Word & $\mathrm{XXX}$ & & Word & Body & $\mathrm{XXX}$ & & \\
\hline \multirow{2}{*}{$\begin{array}{l}\text { Whole word } \\
\% \mathrm{E}\end{array}$} & 761 & 709 & 52 & 689 & 650 & 39 & 650 & 636 & 623 & 14 & 27 \\
\hline & 1.89 & 1.14 & & 3.5 & 1.93 & & 1.04 & 1.34 & 0.92 & & \\
\hline \multirow{2}{*}{$\begin{array}{l}\text { Beginning } \\
\quad \% \mathrm{E}\end{array}$} & 780 & 755 & 25 & 693 & 685 & 8 & 666 & 665 & 668 & 1 & -3 \\
\hline & 1.14 & 0.38 & & 2.29 & 3.33 & & 0.92 & 1.49 & 0.34 & & \\
\hline \multirow{2}{*}{$\begin{array}{l}\text { Middle } \\
\% \mathrm{E}\end{array}$} & 767 & 735 & 32 & - & - & - & - & - & - & - & - \\
\hline & 1.9 & 1.9 & & & & & & & & & \\
\hline \multirow{2}{*}{$\begin{array}{l}\text { End } \\
\% \mathrm{E}\end{array}$} & 792 & 729 & 63 & 705 & 673 & 32 & 694 & 666 & 665 & 29 & 28 \\
\hline & 3.03 & 1.16 & & 3.65 & 2.5 & & 1.38 & 1.62 & 0.56 & & \\
\hline
\end{tabular}

Note-Means of median reaction times (RTs, in milliseconds) and error rates (\% E) as a function of the variables type of printing (whole word, beginning, middle, and end of the word) and string type (incongruent word, body part words, string of Xs, and consonant strings). Stroop effects are also calculated.

longer than $2,500 \mathrm{msec}$ were also excluded from the analysis $(0.3 \%$ of the trials). Means of the median RTs and the error rates for each condition are shown in Table 1 (Experiment 1).

Means of the median RTs were submitted to an analysis of variance (ANOVA) with string type (incongruent word or Xs) and print type (whole word or beginning, middle, or end letter) as within-subjects variables. Error rates were low $(1.1 \%)$ and therefore are not reported. There was a main effect of string type $\left[F(1,21)=52.3, M S_{\mathrm{e}}=1,567.22\right.$, $p<.001]$, with RTs 43 msec longer in the incongruentword condition $(775 \mathrm{msec})$ than in the Xs condition (732 msec). This RT difference reflects the Stroop effect produced by the different word stimuli. The main effect of print type was also significant $\left[F(3,63)=3.29, M S_{\mathrm{e}}=\right.$ $2,579.6, p<.05$ ], with RTs in the whole-word condition shorter than in the remaining conditions. RT analysis for each of the single letter colored conditions revealed shorter latencies in the intermediate positions than at the extremes $\left[F(1,21)=21.1, M S_{\mathrm{e}}=2,143.8, p<.001\right]$. Finally, the interaction between string type and print type was significant $\left[F(3,63)=2.77, M S_{\mathrm{e}}=1,265.9, p<.05\right]$, since Stroop interference was larger in the whole word colored condition [52 msec, $F(1,21)=35.61, M S_{\mathrm{e}}=845.4, p<$ $.001]$ and in the end letter colored condition [63 msec, $\left.F(1,21)=27.8, M S_{\mathrm{e}}=1,593.3, p<.001\right]$ than in either the beginning letter colored condition [ $25 \mathrm{msec}, F(1,21)=$ $\left.3.06, M S_{\mathrm{e}}=2,188.8, p<.09\right]$ or the middle letter colored condition [32 msec, $F(1,21)=5.66, M S_{\mathrm{e}}=949.6, p<$ .03]. Stroop interference did not significantly differ between the beginning and middle letter colored conditions $(F<1)$ and between the whole word and end letter colored conditions $(F<1)$.

\section{Discussion}

In this experiment, Stroop interference was smallest when either the first or middle letter was colored and largest when either the whole word or last letter in the word was colored. This pattern supports the idea that single-letter coloring in the Stroop task attenuates Stroop interference in a position-sensitive manner. We suggest that Stroop in- terference was larger when the end of the word was colored than when the beginning of the word was colored because when the end of the word was colored the initial letter segment, which most strongly activates responses (Singer et al., 1975), was longer (blu in the word blue) than when the beginning of the word was colored ( $b$ in the word blue).

Although the data from Experiment 1 demonstrate that letter segments of partially colored words produce Stroop interference and that the length of the intact initial segment affects the size of this interference, they cannot tell us in what way attentional selection affected Stroop interference. This is because the length of the selected color segments (one letter) was always shorter than the length of the noncolored letters. Selection could have affected processing in several ways. First, ink color selection may entail inhibition of the colored letter. For example, when $b$ in the word blue is colored, the to-be-ignored letter $b$ may be inhibited. Such a finding would be consistent with selection accounts that emphasize inhibition of task-irrelevant information (Houghton \& Tipper, 1994, 1996). The result would be novel in that selection of the task-relevant dimension (color) and inhibition of the task-irrelevant dimension (word) occur within the same object. Second, ink color selection could facilitate processing of the to-beignored colored letter. This account is consistent with a spotlight metaphor of attention, where all features that fall within the focus of attention are facilitated (Posner, 1980). Finally, ink color selection may neither facilitate nor inhibit processing of the colored letter. Evidence in favor of this possibility would indicate that in our task the sole purpose of selection is to permit an overt ink color response. Experiment 2 explored these possibilities.

To explore how selection affects processing of the taskirrelevant word segments, we colored either the first half or the last half of the letters in the letter strings. ${ }^{1}$ This manipulation ensured that the selected and nonselected letter strings were the same length. For example, whether the first two letters or the last two letters of the word blue were colored, the resulting letter segments were $b l$ and $u e$. If ink color selection entails inhibition of the to-be-ignored let- 
ters, then Stroop interference should be smaller when the first half of the word string is colored than when the last half of the word string is colored. This follows because inhibition of word segments that more strongly activate responses (e.g., those at the beginning of a word) should result in less response activation than inhibition of letter segments that less strongly activate responses (e.g., those at the end of a word). For example coloring $b l$ in the word blue would lead to inhibition of the letters $b l$ and leave the letters ue unchanged, whereas coloring ue would lead to inhibition of the letters $u e$ and leave the letters $b l$ unchanged. If on the other hand color selection facilitates features of the irrelevant dimension that fall within the attentional spotlight (Posner, 1980), Stroop interference should be larger when the first half of the letter string is colored than when the last half is colored. This follows because facilitation of letters that more strongly activate responses (e.g., letters at the beginning of a word) should produce more response activation than facilitation of letter segments that less strongly activate responses (e.g., segments at the end of a word). Finally, if color selection entails neither facilitation nor inhibition of the colored letter segments, then interference effects should be equivalent whether the first half or the last half of the word is colored. ${ }^{2}$

\section{EXPERIMENT 2}

\section{Method}

Participants. A total of 20 students from the University of Almería participated for partial fulfillment of a course requirement. All of the participants were right handed, reported normal or corrected-tonormal visual acuity, and were not aware of the experiment's purpose.

Stimuli and Materials. The stimuli were identical to those used in Experiment 1 save for the coloring of the partially colored letter strings. Here half of the letters either at the beginning or at the end of the letter string were colored. For five letter strings, the first three or the last three characters were colored.

Design and Procedure. The experimental design was similar to that of Experiment 1. There were two blocks of 192 experimental trials. Each block consisted of 48 incongruent-word trials with all letters colored, $48 \mathrm{Xs}$ trials with all Xs colored, 48 incongruent-word trials with some letters colored, and $48 \mathrm{Xs}$ trials with some Xs colored. For the partially colored conditions, the trials were separated into two further sets of 24 trials, where either the first or the second half of the string was colored. The temporal parameters and mechanisms to collect the responses were identical to those used in Experiment 1 .

\section{Results}

The RT analysis included only trials with correct responses. Trials with RTs faster than $100 \mathrm{msec}$ or slower than $2,500 \mathrm{msec}$ were also excluded from the analysis $(0.5 \%$ of the trials). Means of the median RTs and error rates for the different conditions are shown in Table 1 (Experiment 2).

Means of the median RTs were submitted to an ANOVA with string type (incongruent word and Xs) and print type (whole word, beginning, and end) as within-subjects variables. Error rates were low (2.7\%) and mirrored the RT data. There was a main effect of string type $[F(1,19)=$
32.6, $M S_{\mathrm{e}}=631.6, p<.001$ ], with RTs 25 msec longer in the incongruent-word condition than in the Xs condition. This effect reflects the averaged Stroop effect produced in the incongruent-word conditions. A main effect of print type was also observed $\left[F(2,38)=5.8, M S_{\mathrm{e}}=\right.$ $892.6, p<.005$ ], with RTs shortest in the whole word colored condition $(665 \mathrm{msec})$, intermediate in the end letter colored condition $(679 \mathrm{msec})$, and slowest in the beginning letter colored condition $(689 \mathrm{msec})$. Following the results of Experiment 1, the string type $\times$ print type interaction was significant $\left[F(2,38)=4.2, M S_{\mathrm{e}}=669, p<\right.$ $.05]$, reflecting the fact that Stroop interference occurred in the whole word colored condition [39-msec Stroop effect, $\left.F(1,19)=20.7, M S_{\mathrm{e}}=500.1, p<.001\right]$ and the end letter colored condition [32-msec Stroop effect, $F(1,19)=$ $\left.13.2, M S_{\mathrm{e}}=786.5, p<.005\right]$, but not in the beginningletter colored condition [8-msec Stroop effect, $F(1,19)=$ $\left.1.2, M S_{\mathrm{e}}=440.1, p<.3\right]$. The magnitude of Stroop interference did not vary between the whole word and end letter colored conditions $(F<1)$.

\section{Discussion}

In this experiment we sought converging evidence for our finding from Experiment 1 that one consequence of coloring a subset of letters in a Stroop task is separate and different processing for the colored and noncolored letter segments. The data support this pattern. When the first half of the word was colored, interference effects were smaller than when the second half of the word was colored. This observation also addresses our question concerning the role of selection in this variant of the Stroop task. Specifically, we suggest that the fact that interference effects were large when the end of the word was colored and absent when the beginning of the word was colored indicates that color selection entails suppression of the to-beignored colored word segment. This finding is consistent with inhibitory models of selection (Houghton \& Tipper, 1994, 1996) and provides novel evidence that selection of a task-relevant dimension can entail inhibition of other dimensions within the same object.

One other important aspect of the data in Experiments 1 and 2 is that whereas RTs for words in the beginning letter colored condition were shorter than in the end letter colored condition, the reverse pattern was true for the Xs condition. This interaction indicates that the status of the letter string (word or Xs) affected participants' ink color responses, despite the fact that letter strings were to be ignored. Although this finding is important because it provides further evidence for word-specific processing in the single letter colored word condition, the fact that the Xs were processed differently than the words raises the question of whether the string of Xs was an appropriate neutral stimulus. ${ }^{3}$ Furthermore, the fact that RTs in the Xs condition were shorter in the end X colored condition than in the beginning $\mathrm{X}$ colored condition contributed to the finding of larger Stroop interference effects in the end letter colored conditions than in the beginning letter colored condition. This is because the interference effect is calcu- 
lated by subtracting RTs in the the Xs condition from the RTs in the incongruent-word conditions. Because of the concern that the Xs condition was processed differently than the word condition an additional experiment was conducted with the same incongruent-word conditions as in Experiment 2, but with two new neutral conditions. The main question was whether Stroop interference with the new neutral conditions would be similar to that found in the previous two experiments.

\section{EXPERIMENT 3}

\section{Method}

Participants. A total of 20 students from the University of Almería participated in partial fulfillment of a course requirement. All of the participants were right handed, reported normal or corrected-tonormal visual acuity, and were not aware of the experiment's purpose.

Stimuli and Materials. The incongruent stimuli were identical to those used in Experiment 2. The Xs condition was modified so that for each incongruent word there was a different string of consonants. This resulted in four new letter strings: XXXXX to match the word verde; YYYY to match the word rojo; MMMM to match the word azul; and WWWWWW to match the word blanco. In addition to the incongruent-word condition and the string of consonants condition, a condition was included that consisted of words representing body parts. These words matched the color words for length: oreja (ear), uñas (nails), caras (face), and pierna (leg).

Design and Procedure. The design was identical to that of Experiment 2 save for an additional 96 trials per block (for a total of 288 trials per block) that consisted of 48 fully colored body part word trials and 48 partially colored body part word trials. The temporal parameters and mechanisms to collect the responses were identical to those used in the previous experiments.

\section{Results}

The RT analysis included only trials with correct responses. Trials with RTs faster than $100 \mathrm{msec}$ or slower than $2,500 \mathrm{msec}$ were also excluded from the analysis $(0.5 \%$ of the trials). Means of the median RTs and error rates for the different conditions are shown in Table 1 (Experiment 3 ).

Means of the median RTs were submitted to an ANOVA with string type (incongruent word, consonant string, and body part words) and print type (whole word, beginning, and end) as within-subjects variables. Error rates were low $(1.06 \%)$ and mirrored the RT data. There was a main effect of string type $\left[F(2,38)=4.9, M S_{\mathrm{e}}=1,082.7, p<.05\right]$, with RTs longest in the incongruent-word condition $(670 \mathrm{msec})$, intermediate in the body parts condition $(656 \mathrm{msec})$, and shortest in the consonant string condition (652 msec). This effect reflects the averaged Stroop effect produced in the incongruent-word conditions relative to the remaining conditions. There was also a main effect of print type $\left[F(2,38)=39.2, M S_{\mathrm{e}}=623.7, p<.001\right]$, with RTs shortest in the whole word colored condition $(637 \mathrm{msec})$, intermediate in the beginning letter colored condition $(666 \mathrm{msec})$, and longest in the end letter colored condition $(675 \mathrm{msec})$. Although the string type $\times$ print type interaction was not significant $[F(4,76)=1.37$, $\left.M S_{\mathrm{e}}=1,324, p=.251\right]$, we analyzed the Stroop effects as a function of print type, as in Experiments 1 and 2. When the incongruent-word condition was compared with the consonant string condition, Stroop interference was significant in the whole word colored condition [27-msec Stroop effect, $\left.F(1,19)=6.4, M S_{\mathrm{e}}=1,119, p<.05\right]$ and the end letter colored condition [29-msec Stroop effect, $\left.F(1,19)=9.1, M S_{\mathrm{e}}=925.7, p<0.0\right]$, but not in the beginning letter condition $(-2$-msec Stroop effect, $F<1)$. Stroop interference did not significantly differ between the whole word and the end letter colored conditions $(F<1)$, but approached significance in the comparison between the beginning and end letters colored conditions $\left[F(1,19)=4, M S_{\mathrm{e}}=989, p<.06\right]$. When the incongruentword condition was compared with the body parts condition, the analyses revealed that although the Stroop effect was significant in the end letter colored condition [28msec Stroop effect, $\left.F(1,19)=4.8, M S_{\mathrm{e}}=1,580, p<.05\right]$, it was not significant in either the whole word colored condition (14-msec Stroop effect, $F=1$ ) or in the beginning letter colored condition (1-msec Stroop effect, $F<$ $1)$. The magnitude of the Stroop effect did not vary between the whole word and end letters colored conditions $(F<1)$.

\section{Discussion}

The aim of this experiment was to examine whether the larger interference effects observed in Experiments 1 and 2, when the ends of words were colored rather than when the beginnings of words were colored, resulted primarily from the comparison of the incongruent condition with a neutral condition that appeared to be processed differently than the incongruent condition. The data indicate that they were not. As in the previous experiments, Stroop interference effects, now calculated relative to both the body part words and the string of consonants conditions, were larger in the end letter colored condition than in the beginning letter colored condition. Furthermore, in the present experiment there was no evidence that in the two neutral conditions there was an orienting bias toward the end of the word, as was observed with the Xs condition in the previous experiments. On these findings we suggest that in the partially colored Stroop task, processing for the colored and noncolored letter segments is separate and different. Furthermore, we suggest that the fact that interference effects were large when the end of the word was colored and absent when the beginning of the word was colored indicates that color selection entails suppression of the to-beignored colored word segment.

\section{GENERAL DISCUSSION}

In a series of experiments we explored the effects of single-letter coloring on word reading in the Stroop task. In each of the experiments we observed larger interference effects when the ends of words were colored than when the beginnings of words were colored. On these findings we suggest that colored and noncolored segments of partially colored words are processed separately and differently, and that selection of the task-relevant color dimension for explicit report entails inhibition of the task- 
irrelevant colored letters. Irrespective of the interpretation of the selection processes involved, our data contribute to elucidating the nature of the interaction between word segmentation and word reading in the single-letter Stroop task (Besner \& Stolz, 1999b; Besner et al., 1997; MaríBeffa et al., 2000). Specifically, the data indicate that the reduction of Stroop interference in the single letter colored condition results primarily from trials in which the first letter of the word is colored. More importantly, our finding that the magnitude of the Stroop effect varies as a function of the position of the colored letters indicates that at least some aspect of the word activation process that is integral to word reading appears to proceed normally in the face of partial word-coloring manipulations.

\section{REFERENCES}

BESNER, D. (2001). The myth of ballistic processing: Evidence from Stroop's paradigm. Psychonomic Bulletin \& Review, 8, 324-330.

BeSner, D., \& Stolz, J. A. (1999a). Unconsciously controlled processing: The Stroop effect reconsidered. Psychonomic Bulletin \& Review, 6, 449-455.

Besner, D., \& Stolz, J. A. (1999b). What kind of attention modulates the Stroop effect? Psychonomic Bulletin \& Review, 6, 99-104.

Besner, D., Stolz, J. A., \& Boutilier, C. (1997). The Stroop effect and the myth of automaticity. Psychonomic Bulletin \& Review, 4, 221-225.

Bibi, U., Tzelgov, J., \& HeniK, A. (2000). Stroop effect in words that differ from color words in one letter only. Psychonomic Bulletin \& Review, 7, 678-683.

Coltheart, M., \& Rastle, K. (1994). Serial processing in reading aloud: Evidence for dual-route models of reading. Journal of Experimental Psychology: Human Perception \& Performance, 18, 643-661.

Coltheart, M., Woollams, A., Kinoshita, S., \& Perry, C. (1999). A position-sensitive Stroop effect: Further evidence for a left-to-right component in print-to-speech conversion. Psychonomic Bulletin \& Review, 6, 456-463.

Houghton, G., \& Tipper, S. P. (1994). A model of inhibitory mechanisms in selective attention. In D. Dagenbach \& T. Carr (Eds.), Inhibitory processes in attention, memory and language (pp. 53-112). San Diego: Academic Press.
Houghton, G., \& Tipper, S. P. (1996). Inhibitory mechanisms of neural and cognitive control: Applications to selective attention and sequential action. Brain \& Cognition, 30, 20-43.

Kahneman, D., \& ChajczyK, D. (1983). Tests of the automaticity of reading: Dilution of Stroop effects by color irrelevant stimuli. Journal of Experimental Psychology: Human Perception \& Performance, 9 , 497-509.

Kahneman, D., \& Henik, A. (1981). Perceptual organization and attention. In M. Kubovy \& J. R. Pomerantz (Eds.), Perceptual organization (pp. 181-211). Hillsdale, NJ: Erlbaum.

MACLEOD, C. M. (1991). Half a century of research on the Stroop effect: An integrated review. Psychological Bulletin, 109, 163-203.

Marí-Beffa, P., Estévez, A. F., \& Danziger, S. (2000). Stroop interference and negative priming: Problems with inferences from null results. Psychonomic Bulletin \& Review, 7, 499-503.

Posner, M. I. (1980). Orienting of attention. Quarterly Journal of Experimental Psychology, 32, 3-25.

Singer, M. H., Lappin, J. S., \& Moore, L. P. (1975). The interference of various word parts on color naming in the Stroop test. Perception \& Psychophysics, 18, 191-193.

Stroop, J. R. (1935). Studies of interference in serial verbal reactions. Journal of Experimental Psychology, 18, 643-661.

\section{NOTES}

1. Our discussion is restricted to the consequences of color selection on processing of the task-irrelevant colored letter segments. It is also possible that selection affects processing of the noncolored letter segments. In any case, the data indicate an asymmetric effect of selection on processing of the colored and noncolored segments. If, for example, as a consequence of selection both colored and noncolored segments were inhibited equivalently, then interference effects should have been identical whether the first or second half of the word was colored. The same pattern holds true for a facilitatory account of selection.

2. We would not expect equivalent interference in Experiment 1 because segmentation in that experiment produced word segments that differed in content (e.g., blu and $e$ as opposed to $b$ and lue).

3. We thank our reviewers for pointing this pattern out to us and suggesting that we conduct a modified version of Experiment 2 with a more appropriate neutral condition.

(Manuscript received March 29, 2000; revision accepted for publication August 21, 2001.) 